\title{
Analysis of Verbal Interactions Between Brazilian Students in a Physics Investigative Activity Class With STS Approach: A Case Study
}

\author{
Roberto Barreto de Moraes ${ }^{1}$, Deise Miranda Vianna ${ }^{1,2}$ \\ ${ }^{1}$ Institut of Physics, Federal University of Rio de Janeiro, Brazil \\ ${ }^{2}$ Oswaldo Cruz Institut, Fiocruz, Rio de Janeiro, Brazil \\ Correspondence: Deise M. Vianna, Av. Athos da Silveira Ramos, Centro de Tecnologia - Bloco A, Cidade Universitária, \\ CEP: 21941-972. Rio de Janeiro, RJ, Brasil.
}

Received: September 25, 2021

Accepted: October 15, 2021

Online Published: October 17, 2021

doi:10.11114/jets.v10i1.5361

URL: https://doi.org/10.11114/jets.v10i1.5361

\begin{abstract}
This article presents results on the analysis of verbal interactions of students from a federal public high school in Rio de Janeiro, Brazil, during an investigative activity class about the properties of magnets. This experimental assignment was part of a didactic sequence developed for the study of Electromagnetism, which was structured using a Science, Technology and Society (STS) approach combined with the investigative activities method, in which students divided into groups carried out a series of experimental essays on the contents that were presented to them. The objective was to determine if students were able and capable of structuring their own causal statements to a problem involving knowledge of Physics, when given the proper conditions to work with an experimental setup. Differently from the traditional transmission-reception didactic model, the STS didactic orientation seeks out to incorporate the scientific syllabus into the students' daily life relationships. A qualitative methodology was used from the transcriptions of video and digital audio recordings that were registered during classes, some scenes of an educational episode were selected and the verbal interactions of the students among themselves were analyzed, looking for some indicators that could identify whether scientific literacy was accomplished. Analysis showed evidence that students were able to construct meaning with their own words by reasoning about what was observed in the experiments performed.
\end{abstract}

Keywords: physics education, investigative activities, scientific literacy, sts approach

\section{Introduction}

\subsection{Introduce the Problem}

The low performance and indifference shown by the students in Science classes reveal the need for reconfiguration and transformation of science classrooms at schools in Brazil. Researchers in Brazilian Education seek to establish strategies that could enable the theoretical and methodological innovations to reach schools' classrooms. However, it is not uncommon that the results of these developments are not able to pass through the barriers within the system.

It is important for students to realize that the contents covered in science classes are closely related to their everyday life, to the social, political and economic transformations that guided the course of society as a whole and, consequently, of their lives. As advocated by Lev Vygotsky, learning (as well as teaching) is a primarily collective experience: it is through interactions with others, whether more or less experienced, that knowledge is built (Karpov, 2014).

This concept of interaction reveals a typically human trait, which is the ability to articulate language to appropriate a set of symbolic representations and forms of expression that can acquire meaning within the social interaction. Learning Science necessarily requires the use of a plurality of means of communication in a coordinated fashion, and the way to achieve such multiplicity in the classroom necessarily involves interaction between the subjects involved (Martins, Ogborn, \& Kress, 1999). The implemented activities must, therefore, privilege discussions, debates, presentations of ideas and perceptions of students regarding a concept or a phenomenon.

Thus, efforts in the production and analysis of new possibilities of didactic sequences elaborated under the Science, Technology and Society (STS) approach with elements of investigative activities assumes a current and innovative model capable of forming citizens scientifically literate. One of the central objectives of the STS movement demands that decisions regarding Science and Technology should be more democratic, where more social actors participate, 
shifting the main focus of the content to a more comprehensive approach, giving the students autonomy to take a stand in the face of social conflicts that will be faced ahead (Aikenhead, 2005). The different scientific and technological applications should enable the students to understand the reality around them, so that they can participate in a critical and conscious way in society. Thus, in addition to the presentation of specific content, the activities developed under this approach should contain elements that can develop the ability of students to take positions in the face of controversial problems, and act to resolve them (Cowan \& Maitles, 2012).

This article aims to present analysis of speeches of high school students working in collaborative task in an investigative activity on the properties of magnets. It is also important to state at this point that this research was developed and applied in the years before the covid-19 pandemic outbreak, when students were normally taking in-person classes. Initially, aspects of the theoretical framework on argumentation in the classroom will be presented, as well as aspects of qualitative research methodology in Science/Physics teaching. It will be sought indicators of scientific literacy that could demonstrate whether, in the classroom, when given the conditions to solve an experimental problem involving knowledge about Magnetism, the students are able to structure their own causal explanations about the phenomena observed during the experiments. Next, it will be highlighted the theoretical references involved, as well as the development of the activity in the classroom following the data collection of the research carried out.

\section{Verbal Interactions of Students in Science Classrooms}

There are several forms of language that are combined to fulfill the goal of a more effective communication. When observing language as a social practice where meanings are constructed, specific elements of each culture are necessarily resorted to, such as gestures, actions and idiomatic expressions.

There are several discursive interactions that can occur in a classroom, for example, during the oral presentation of an idea, while reading or writing a written text, during work with graphics, images or audiovisual resources, as well as there are equally numerous the possible relationships between knowledge that can be generated or reinforced during the teaching and learning process (Sasseron \& Carvalho, 2011, p. 98).

Jiménez-Aleixandre and Bustamante (2003) emphasize the importance of students' speech in Science classes. According to the authors, argumentation is the ability to relate data and conclusions, to evaluate theoretical statements in the light of empirical data or those coming from other sources. Sasseron and Carvalho (2008) understand argumentation as any and all discourse in which student and teacher present their opinions in class, describing ideas, presenting hypotheses and evidence, justifying actions or conclusions reached, and explaining results achieved.

For instance, language has a primary role in the genesis of causal explanations. Thus, when analyzing the verbal and non-verbal interactions (such as gestures, drawings, writings, etc.) that can occur in classes, it can observed whether students can raise hypotheses based on their prior knowledge, if they use the "if/then/therefore" hypothetical-deductive reasoning, if they develop proportional reasoning when performing qualitative analyses, and if they are able to contextualize knowledge with the society around them. Carvalho (2005) proposed an analysis of the verbal interactions of teachers and students to show whether or not students achieved standards of scientific reasoning, and whether teachers created an environment conducive to the scientific development of their students.

Those analyses would allow to identify whether the contextualization of the theme, as well as the ordering of scientific contents addressed in a didactic sequence, enabled students to engage in discursive actions related to the resolution of issues and problems involving the complex relationships between Science, Technology and Society.

Investigative activities should be based on the students' actions, in a way that the experimental classes should not be limited to simple observations. To solve a problem via experimentation involves manipulation, but also reflection, pondering, reports, discussions, and explanations. Firstly, conditions must be created in classrooms for students to reflect and develop theoretical and/or experimental hypotheses about the topic addressed. It is necessary that the students understand what they did, seeking a line of reasoning and thoughts: about "how" they managed to solve the problem and "why" it worked (Tao \& Gunstone, 1999).

\subsection{The Use of Language and Argumentation in Science Teaching}

For students to present their thoughts during classes, it is essential to plan an activity that provides the opportunity to promote broad participation and involvement, but, moreover, the teacher/professor needs to be prepared to act as a promoter and mediator of argumentations and debates in class, both between teacher and students, and also students among themselves. Thus, the matter of how argumentation happens in the classroom and its role in the construction of knowledge by students, arises as a need to find an answer to a question that can be theoretical or practical.

There are significant differences between research methodologies when the questions are: "how much is learned" and "how is it learned" (Carvalho, 2005). In the present case, the interest lies in whether students can perceive Science as a social construction when they participate in an investigative activity, and what are the teaching conditions to make 
possible the students' arguments and debates. Gomez, Carvalho and Sasseron (2015) highlight how research in Science Education has verified the role of language, noting the importance of "discursive interactions between teacher and students", based on sociological and philosophical perspectives of Science identified as a social activity, by which scientific knowledge can be built, debated and understood in classrooms. According to Machado and Sasseron (2012), the discursive aspects of investigative education are the following: the creation of the problem; working with data; the investigation process; and the explanation and/or internalization of concepts.

In general, high school students are not yet able to elaborate highly complex scientific arguments, as their knowledge of Physics is still somewhat restricted. The objective, therefore, should be to promote the Scientific Enculturation of students, i.e., to insert them into a new culture permeated with codes, symbols, values, practices and language specific to scientific practice. In this sense, the social space of classrooms should enable the main aspects that surround scientific practices in a matter that it is possible to find ways to present the concepts and notions of Physics and Sciences (Driver, Asoko, Leach, Mortimer, \& Scott, 1994).

Argumentative language plays a central role in Physics. In teaching activities in which students need to analyze phenomena and debate "scientific facts", they must provide justifications that are duly consistent. Thus, the more the context is in the student's domain, the merrier one can develop causal relations (Carvalho, 2004). In the field of Physics, in addition to argumentative language, it is essential to consider mathematical language as a strictly necessary mode of communication in the construction of ideas and dissemination of knowledge.

\subsection{Scientific Literacy Indicators in Investigative Classes}

An investigative activity (not necessarily in a laboratory) must be accompanied by a problematizing and dialogic situation. For an activity to be classified as investigative, the student's action should not be limited only to manipulation or observation, it should contain characteristics of a scientific investigation through reports, reflections, discussions, and explanations by the students. In a didactic sequence proposition, different formats of investigative activities can be used, such as: open-ended laboratory, investigative demonstrations, open-ended questions, investigative visits, informal practices and open-ended problems (Penha, 2006). Checking the student's prior knowledge is also a part of an investigative class, as the student needs to recognize the proposed problem and understand it in order to seek its resolution.

Based on their studies on argumentation, Sasseron and Carvalho (2008) developed the concept of scientific literacy indicators that represent the discursive skills and actions articulated by students, later expanded by Penha, Carvalho and Vianna (2015), represented in Table 1. These scientific literacy indicators have the function of showing skills that appear when scientific literacy is under development, dividing them into groups: those linked to data collection and research variables; those that are related specifically to the work with the data obtained; those that encompass the structuring of the statements made and the construction of logical and objective ideas; and those which are most directly linked to establish an understanding of the situation analyzed (Sasseron \& Carvalho, 2008). Penha et al. (2015) expanded this understanding of scientific literacy indicators, also taking into account those that seek to develop experimental procedures and strategies during the research activity. 
Table 1. Scientific literacy indicators, their functionalities and occurrences

\begin{tabular}{|c|c|c|}
\hline Functionalities & Scientific literacy indicators & Indicator occurrence \\
\hline $\begin{array}{l}\text { Indicators related to the acquisition of } \\
\text { experimental data, identification of } \\
\text { variables and analysis of the relations } \\
\text { between them }\end{array}$ & Procedural strategies & $\begin{array}{l}\text { While handling objects and/or } \\
\text { experimental apparatus, procedural } \\
\text { strategies are elaborated in order to } \\
\text { understand how to act with such objects }\end{array}$ \\
\hline \multirow{3}{*}{$\begin{array}{l}\text { Indicators related to working with } \\
\text { empirical data and to the way the } \\
\text { investigation is carried out }\end{array}$} & Information classification & $\begin{array}{l}\text { Ordering and relating the elements that } \\
\text { are worked with }\end{array}$ \\
\hline & Information serialization & $\begin{array}{l}\text { Seeking to establish bases for an } \\
\text { investigative action }\end{array}$ \\
\hline & Information organization & $\begin{array}{l}\text { Searching for an arrangement is made } \\
\text { explicit with the available information }\end{array}$ \\
\hline \multirow{2}{*}{$\begin{array}{l}\text { Indicators related to structuring } \\
\text { analytical thinking and appropriation of } \\
\text { scientific terms }\end{array}$} & Logical reasoning & $\begin{array}{l}\text { Understanding how ideas are developed } \\
\text { and presented }\end{array}$ \\
\hline & Proportional reasoning & $\begin{array}{l}\text { Understanding how the } \\
\text { interdependence of the variables is } \\
\text { structured }\end{array}$ \\
\hline \multirow{3}{*}{$\begin{array}{l}\text { Indicators related to raising assumptions } \\
\text { about the experiment, variables and } \\
\text { ideas. }\end{array}$} & Hypothesis survey & $\begin{array}{l}\text { Assumptions are being raised. It can } \\
\text { appear either in the form of questions or } \\
\text { statements }\end{array}$ \\
\hline & Prediction & $\begin{array}{l}\text { Assumption that an action and/or a } \\
\text { phenomenon happened because of a } \\
\text { certain event }\end{array}$ \\
\hline & Hypothesis test & $\begin{array}{l}\text { Previously raised assumptions are put to } \\
\text { the test }\end{array}$ \\
\hline \multirow{2}{*}{$\begin{array}{l}\text { Indicators of the search for relations } \\
\text { between variables and informations, } \\
\text { while seeking to understand the } \\
\text { analyzed situation }\end{array}$} & Explanation & $\begin{array}{l}\text { Seeking to relate information and } \\
\text { hypotheses already raised. }\end{array}$ \\
\hline & Justification & $\begin{array}{l}\text { Affirmation given while using a } \\
\text { guarantee for what was proposed }\end{array}$ \\
\hline
\end{tabular}

The presence of one indicator does not make the manifestation of others unfeasible, on the contrary, during the argumentations, it is likely that the indicators demonstrate support among themselves for the explanation that is being carried out at a given time by the student.

\section{Methodology}

This research was developed with students from 3 different classes of the senior year of a Federal Public High School located at the city of Rio de Janeiro, Brazil. The classes had, on average, about 30 students per class, all of them native (Brazilian) Portuguese speakers.

A didactic sequence entitled "Physics and Society on TV" (Vianna \& Bernardo, 2012) was developed for the study of Electromagnetism with those high school students. In this sequence, a STS approach combined with the methodology of investigative activity was used to structure different theoretical and experimental activities such as workshops, conferences, round tables, among others. The workshops and conferences were developed in the form of investigative activities, in which groups of students carried out a series of investigations on the contents of Electromagnetism, in order to understand the different technological devices that were being studied and worked on. The syllabus was presented as a consequence of the need to understand these technological devices. The didactic sequence as a whole was applied during a school term.

With the students of each class divided into groups of 4 or 5 people per group, the recordings of all activities were carried out using a video camera mounted on a tripod and digital audio recorders distributed to each of the groups involved in the activities.

This research follows a qualitative design, as it uses interpretations of speech, writing, gestures and actions of students during classes. The data collected is predominantly descriptive, as the objective is to describe the process of scientific enculturation of students. A delicate issue in qualitative methodology refers to the validity and reliability of the results obtained (Moreira, 2018). Validity is about the commitment to actually measuring what it is wanted, thus, it is related to the overall planning of the data recording process. Reliability concerns the accuracy of measurements.

In order to avoid possible interferences that could arise due to the insertion of recording equipment (and the operator of such instruments) in the classroom environment, some procedural precautions were taken as to initially get the class used to the person who would record the data. Thus, the recordings were started some classes before those planned to 
obtain the research data, so that the students and the teacher were already used to those equipments (and person) as part of the class and all curiosity had already been calmed down.

From a theoretical point of view, one cannot state that there is no interference at all, as each and every instrument interferes with the phenomenon to be studied, for example: a voltmeter modifies the electrical voltage it intends to measure, just as a thermometer exchanges heat with the body it measures and thus the value shown is necessarily changed, but evidently there would be no evolution of Science and explanations of nature's phenomena if there were no use of measuring instruments. In fact, the lens of a camera and/or the diaphragm of a recorder, embodied in the classroom with a researcher behind them, allow us to go beyond the limits of what is observable in the case of education, teaching and learning processes, and leads us, without a doubt, to a paradigm shift in didactic research.

Audio and video recordings are not simple and straight research data, in order to transform the classes' recordings into research data, it is necessary to select what Carvalho (2005, p. 35) called "educational episodes", i.e., "moments extracted from a class, where it is evident that occurs an educational situation that can be investigated". The episode is part of a whole process in that class and thus a clipping is made, where a selected sequence of key-situations are observed and analyzed. While watching the videos and/or listening to the audio recordings made, it can be noted that the same educational episode may not be continuous. In other words, the episode analyzed can have its sequence interrupted, continuing minutes after or even in later classes. For that matter, the episodes can also be subdivided into smaller intervals, called "scenes".

During the application of the entire didactic sequence, on average about 10 hours of video and 42 hours of audio were recorded for each of the 3 classes. Then the recordings were debugged, decoupled and transcribed. In this sense, it is up to the researcher to work very close to a producer or editor of a film, assembling the various scenes of an episode to make sense of its data, as the dialogues in the classroom are not straight forward, given the obvious difficulty of the process of building knowledge led by the students and the slowness that changes are processed from spontaneous to (a kind of) scientific knowledge, from the participations of students and teacher throughout the classes. An excerpt of all this raw recorded material, namely one selected educational episode will be presented in next topic.

The transcripts were faithful to the speeches they corresponded to, considering the translation between Portuguese and English. Regarding the correction of concordance errors, resorting to ethical positions, and considering the difference between spoken and written language, it was chosen to keep any slang, idiomatic expressions and language vices in the transcriptions, thus seeking to maintain greater fidelity to the raw material. Another important aspect to consider in the transcriptions is the possibility of not losing information about intonation, pauses, humor, degree of certainty in the statements, implied words, among others. Lemke (1998) draws attention to the importance of preserving these considerations in the records, aiming at a detailed analysis of them.

\section{Analysis of a Selected Educational Episode}

An educational episode consisting of five scenes taken from audio and video recordings of one of the activities of the applied educational sequence called: "The compass and magnetism: the development of an orientation technique" is analyzed. This sequence aimed the study of compasses' operation, proposing a series of investigations on the magnetic properties of different magnets. The activity consisted in identifying whether all points on the surface of a magnet have the same attractive/repulsive capacity.

For this purpose, it was proposed that the students, using a small pendulum formed by a non-magnetized clips tied on a string, should investigate whether all points on the surface of two different magnets had the same polarizations: a bar-shaped magnet (in which the magnetic poles are on the smaller surfaces of the element) and a plate-shaped magnet (in which the magnetic poles are on the larger surfaces of the object), as shown in Figure 1.

bar-shaped magnet

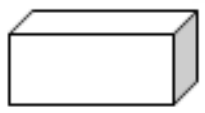

plate-shaped magnet

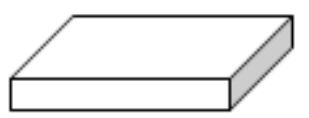

Figure 1. Magnets used in the proposed investigative activity

The scientific literacy indicators shown in Table 1 will be used in order to carry out the qualitative analysis of the transcribed speeches. The episode where the students structure their investigations about the magnets' polarization is transcribed below. The insertions between square brackets with letters in italics represent the present authors' notes 
about the dialogues carried out between the students, in order to settle vague terms that would lead to a difficult understanding of the scenes and the episode.

The following transcriptions refer to a group formed by four students identified by S1, S2, S3 and S4. Their names were changed to letters in order to keep their identities preserved.

The activity begins by reading the textbook statement, where the students themselves, with the class already divided into groups, perform it. As there is no actual indication of a possible "better" way or form of using and configuring the clips and string (and consequently, the pendulum), nor about the magnets (besides merely visual), there is an initial hesitation about how they should proceed to carry out the experiment.

In Scene 1, the students ask each other about the difference between the magnets provided, as transcribed in Table 2, which suggests that at this point the students were seeking to identify the objects, and trying to create a strategy to develop the content of the activity.

Table 2. Scene 1: procedural strategies

\begin{tabular}{l|l|l|l}
\hline Turn & Student & Speech transcription & Indicator \\
\hline 03 & S2 & What do we have to see? & \\
\hline 04 & S3 & $\begin{array}{l}\text { We have to see if all parts of the magnet's surface } \\
\text { attract! }\end{array}$ & Procedural strategies \\
\hline 05 & S2 & Do they have the same [polarization]? & Procedural strategies \\
\hline 06 & S1 & I don't think so! & Procedural strategies \\
\hline 07 & S2 & Is the plate equal to the bar? & $\begin{array}{l}\text { Here... see it? [showing how the magnets are } \\
\text { different from each other] }\end{array}$ \\
\hline 08 & S1 & Oh, cool! & \\
\hline 09 & S2 & Inforganization \\
\hline
\end{tabular}

During Scene 1, student S2 was pointing the magnets to his groupmates, asking them if it would be enough to carry out the experiment with only one of the magnets arranged. It is noticeable that initially there was a great amount of doubt among the group members whether there were an excess of devices (or possible redundancies) that were provided as experimental material by the class teacher. Therefore, when analyzing the devices that were given and identifying the ways to use them, the students would be structuring the procedures to be employed during the investigation.

Then, observations of the phenomenon begun and the debates took shape in the group. The students started to point out that there were at both poles of the magnetic elements an attraction pull, identified by the discussion on the "sides" of the magnets. However, they hesitate about what would be the difference between the attractive forces applied by the plate-shaped magnets and by the bar-shaped ones (Table 3 ).

Table 3. Scene 2: doubts and hesitations

\begin{tabular}{l|l|l|l}
\hline Turn & Student & Speech transcription & Indicator \\
\hline 10 & S4 & $\begin{array}{l}\text { Isn't it better to leave the magnet on the table and } \\
\text { go with the clips over it? }\end{array}$ & Procedural strategies \\
\hline 11 & S1 & $\begin{array}{l}\text { What do you mean? } \\
\text { Leave the magnet on the table... And then pass with } \\
\text { the clips over it lightly... }\end{array}$ & Procedural strategies \\
\hline 12 & S4 & Hmm... I don't know... & \\
\hline 13 & S1 & Here, look! [pointing out the bar-shaped magnet] & \\
\hline 14 & S3 & $\begin{array}{l}\text { Hold on! Turn it over! } \\
\text { On the other side, look... }\end{array}$ & Information serialization \\
15.1 & S1 & $\begin{array}{l}\text { But also this one? [showing out the plate-shaped } \\
\text { magnet] }\end{array}$ & \\
\hline 16 & S2 & Here? No, it doesn't... damn! I don't know... & Prediction \\
\hline 17 & S1 & $\begin{array}{l}\text { No! I think the poles are on the side... } \\
\text { Wait... the clips is pointing this way! }\end{array}$ & Prediction \\
\hline 18.1 & S3 & Oh... I think they are all the same! & \\
\hline 19.2 & S2 & Shat at th point they wer facing a procedural mismatch within the group.
\end{tabular}

It is noteworthy, however, that at this point they were facing a procedural mismatch within the group. They directly hold the clips against the magnets without using it tied to the string like a pendulum, somewhat even rubbing them together (turns 10 to 13). As the experimental setup were still not ideal, their doubts were accumulating as observed in turns 17 to 19 during Scene 2 (Table 3). 
After some minutes of unfruitful discussions and debates about the best way to perform the activity, S1 decides to look for a new experimental strategy, raising the string with the clips tied in, leaving it hanging in the air, instead of rubbing it against the magnets. So at this point, the experimental strategy became totally different from the one that was being carried out so far: with the pendulum formed by the string tied to the clips suspended, one of the magnets is slowly brought closer to the end of that set (Figure 2).

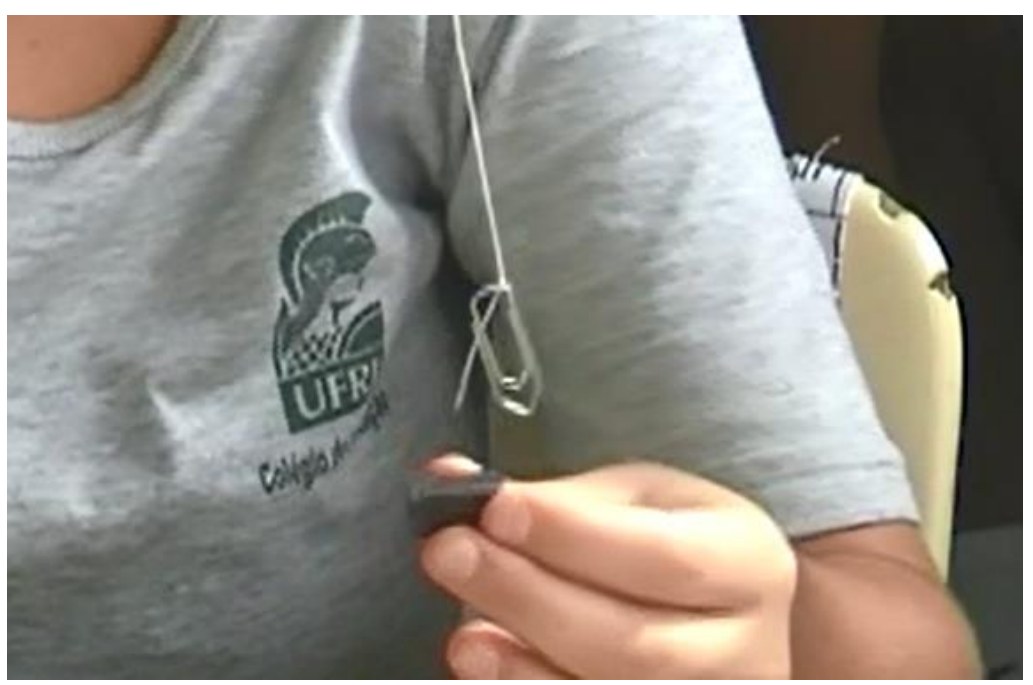

Figure 2. The students change their experimental strategy: with the pendulum formed by the string tied to the clips suspended, one of the magnets is slowly brought closer to the end of that set.

Scene 3 then begins with a surprise interjection (turn 26). The students, which until then were full of disappointment for having spent several minutes accumulating doubts and no conclusions reached, became then positively engaged in the activity. With the new strategy that allowed them to verify the hypotheses of the problem, the literacy indicators for obtaining the data finally emerged (Table 4).

Table 4. Scene 3: understating the experiment and its variables

\begin{tabular}{|c|c|c|c|}
\hline Turn & Student & Speech transcription & Indicator \\
\hline 26 & S1 & Wow!! Did you see it?! & \\
\hline 27 & S2 & Yea!! Guys! Are you seeing it? & \\
\hline 28 & S3 & Oh, amazing!! Try it with both magnets! & \\
\hline 29 & S1 & $\begin{array}{l}\text { That's the way! Now, if I put it on this side here, the } \\
\text { polarization is different! [showing the colleagues the } \\
\text { differences between plate and bar-shaped magnets] }\end{array}$ & Hypothesis test \\
\hline 30 & S3 & And this one? [showing the bar-shaped magnet] & Information classification \\
\hline 31 & S1 & $\begin{array}{l}\text { On the edges! The polarizations are on both sides, look! } \\
\text { [pointing out the bar-shaped magnet] }\end{array}$ & Explanation \\
\hline 32 & S4 & $\begin{array}{l}\text { And here?... [the student takes back the plate-shaped } \\
\text { magnet] }\end{array}$ & Information classification \\
\hline 33 & $\mathrm{~S} 2$ & $\begin{array}{l}\text { Not this one! This one is in the center! See it? [showing } \\
\text { the plate-shaped magnet] }\end{array}$ & Explanation \\
\hline
\end{tabular}

Following that, a short sequence of the students showing each other different attraction pulls coming from different points of the magnets. Finally agreeing that there are sides with greater power of attraction/repulsion, setting out to identify them as the poles of the magnets.

They then picked up similar magnets, and through some repetitions they observed the same phenomenon occurring over and over, and soon began to look for a more consistent hypothesis and formulations (Table 5). At this point with the procedure around the setup already properly figured out, and the experimental reiteration being carried out by the members of the group, the literacy indicators that demonstrate the search for understanding and explaining the phenomena begun to appear. 
Table 5. Scene 4: testing the raised hypotheses

\begin{tabular}{l|l|l|l}
\hline Turn & Student & Speech transcription & Indicator \\
\hline 35 & S3 & $\begin{array}{l}\text { This one is more in the center, isn't it? [pointing out the } \\
\text { plate-shaped magnet] }\end{array}$ & Hypothesis survey \\
\hline 36 & S2 & $\begin{array}{l}\text { Yea! If you drop it [the pendulum], it will point to the } \\
\text { center! }\end{array}$ & Hypothesis test \\
\hline 37 & S3 & $\begin{array}{l}\text { It points here, isn't it? It runs towards the center. This one } \\
\text { doesn't... [pointing to bar-shaped magnet] }\end{array}$ & Hypothesis test \\
\hline 38.1 & S1 & $\begin{array}{l}\text { See it? It points this other way! [showing the difference } \\
\text { between the plate-shaped magnet and the bar-shaped } \\
\text { one] } \\
\text { Let me see this other one... this one is also the same } \\
\text { thing! It's in the center! [performing a test with another } \\
\text { plate-shaped magnet] }\end{array}$ & Logical reasoning \\
\hline
\end{tabular}

It is observed in Scene 4 (Table 5), the construction of understanding and explanation by the students, which involved the way the arguments were unleashed, and the way in which the relations between the variables, objects and apparatus were established from the beginning of the procedural strategies developed by the group, until the point where the whole experiment was well understood and then they could manage to replicate it.

After repeating the experiment a few more times, they were able to formulate an explanation based on all the observations they made, arguing among them about the phenomenon and reaching a consistent conclusion, as shown in Table 6.

Table 6. Scene 5: final explanations and conclusions

\begin{tabular}{l|l|l|l}
\hline Turn & Student & Speech transcription & Indicator \\
\hline 41 & S4 & What do you think? Which sides? & Information organization \\
\hline 42 & S1 & $\begin{array}{l}\text { The clips goes to its ends when it's the bar magnet, and it } \\
\text { goes to the center when it's the plate! }\end{array}$ & Explanation \\
\hline 43 & S4 & $\begin{array}{l}\text { I think so! With this one [the bar-shaped] it's only at its } \\
\text { ends... because of the poles! }\end{array}$ & $\begin{array}{l}\text { Explanation } \\
\text { Justification }\end{array}$ \\
\hline 44 & S2 & Yea! & \\
\hline
\end{tabular}

After the simple and affirmative interjection of turn 44, there was a general feeling among the group members that the conclusions they reached together were satisfactory and convincing, and then they took their final annotations. Through observations of the phenomenon and internal discussions they were able to correctly identify the polarization of the magnets used in the activity.

The transcription of this particular episode shows the active participation of the students in the construction of scientific concepts concerning magnets. They observed, manipulated, investigated and discussed, as evidenced in turns 10 to 33 , where the students experimentally investigated the best way to use the "pendulum made with a string and a clips" and the different magnets to carry out the experiment, going from the speeches and reactions of disappointment by the strategy which was clearly not satisfying to them, until the euphoria with the realization that the best procedure had been achieved.

It is perceived through the argumentative dialogue an exchange of ideas and verbalization among the students of issues brought by the experiment, a strong interaction between the group participants in search of solutions to the problem throughout the scenes. The confrontation of different ideas raised by the group members is clear, in addition to the characteristics of scientific investigation work when a student seeks to convince their "research peers" about the elaborated hypothesis.

The satisfaction related to scientific discovery, represented in turns 26 to 28,43 and 44 is noticeable. The students, after elaborating the investigation strategies, demonstrate their rejoicing with the new discoveries. Thus, it is evident in these transcripts that this investigative activity fulfilled its function of giving the students' work in the classroom similar characteristics to a scientific investigation one. When students are encouraged to tell how they solved the problem, they begin to become aware of the coordination of the events, reasoning about what was done, the phenomena glimpsed in the experiment, the elements that were manipulated, and what their colleagues also observed, so that they can then 
speak, tell, justify, argue and counter-argue with their colleagues and teacher.

The awareness is, therefore, far from constituting just a simple reading: it is a reconstruction made by the students of their actions and of what they were able to observe during the experiment. Thinking about what had been worked and done, the student makes logical connections, establishing associations between the actions and reactions to the objects. The causality in explanations is now entirely attributed to the physical phenomenon.

The selected excerpts tell what happened throughout this activity, those were the dialogues produced by those students who participated in that investigative activity, therefore, it is not possible, nor would it be the intention (much less the pretension), to state that the debates held by those students would represent precisely any other possible, nor exhaust the subject. But we hope to have contributed, acknowledging this example of a debate among students, with the conviction that scientific controversies can be ways to consolidate the learning of central concepts in Physics, such as Magnetism.

It is important to state that this paper presented a slight excerpt of all the raw material of about 10 hours of video and 42 hours of audio that were recorded for each of the 3 classes, namely the selected educational episode that was presented and analyzed. Further studies and future works should bring more analysis of the data that was recorded during that period in those classes.

\section{Final Considerations}

The application of this activity made the students involved with the proposed investigation with great determination and interest. The verbal interactions established by the students during the activity were not restricted to simple statements, but often appeared linked to logically constructed justifications and judgments. The identification of the presence of scientific literacy indicators during the performance of these activities provides evidence that a process of scientific enculturation of students was underway.

It is worth noting that these discussions led students to use the skills of Scientific Culture, the proposed activities led to discussions in which students built links between the knowledge of Science and Technologies associated with knowledge concerning the Magnetism phenomena.

In education, teaching and learning must happen together. Therefore, Physics classes should be planned in a way that the students go beyond mere contemplation, and move towards reflection and the search for explanations and inferences about the most diverse subjects within the scientific scope.

When teaching science or any other subject in the school curricula, it is not intended that students just repeat the words spoken by the teacher as robots or simply copy the content present on the blackboard acting as mere copyists. As stated by Lemke (1997), it is desired that "they should be able to construct essential meanings in their own words". In this sense, when students participate in activities in which they can act actively in the choices of a didactic investigation, they are able to build their own causal explanations.

The students, when given the conditions to solve experimental problems involving knowledge of Physics, can structure their own causal explanations, following a sequence of steps: starting by becoming aware of their actions, and then gradually detaching themselves from their own actions, establishing connections between the the objects studied, including in this process the explanation of new concepts and conceptions. By using the scientific literacy indicators in the analysis of selected scenes of this didactic sequence, we seek precisely to highlight these specific competencies of scientific practices.

Finally, it is expected that students can build not only an understanding of the contents, but also especially knowledge about Science itself, the mutual influences between Science and Society, and ways of building scientific knowledge. This could contribute, combined with other areas of knowledge, so that students have a broader, conscious and critical view of humanity, society and the community of which they are part of. A great contribution from the Natural Sciences is associated with the "scientific knowhow" itself and its organizational characteristic that is simultaneously disciplined, orderly, systematic and creative.

\section{References}

Aikenhead, G. S. (2005). Science Education for Everyday Life: Evidence-Based Practice. Teachers College Press.

Carvalho, A. M. P. (2004). Building up explanations in physics teaching. International Journal of Science Education, Abingdon, 26(22), 225-237. https://doi.org/10.1080/0950069032000052072

Carvalho, A. M. P. (2005). Metodología de investigación en enseñanza de física: una propuesta para estudiar los procesos de enseñanza y aprendizaje. Revista de Enseñanza de la Física, 18(1), 29-37.

Cowan, P., \& Maitles, H. (2012). Teaching Controversial Issues in the Classroom: Key Issues and Debates. London: Continuum. 
Driver, R., Asoko, H., Leach, J., Mortimer, E., \& Scott, P. (1994). Constructing scientific knowledge in the classroom. Educational Researcher, 23(7), 5-12. https://doi.org/10.3102/0013189X023007005

Gomez, Y., Carvalho, A. M. P., \& Sasseron, L. H. (2015). Catalizar la alfabetización científica. Una vía desde la articulación entre enseñanza por investigación y argumentación científica. Revista de Enseñanza de la Física, 27(2), 19-27.

Jiménez-Aleixandre, M. P., \& Bustamante, J. D. (2003). Discurso de aula y argumentación en la classe de ciencias: cuestiones teóricas y metodológicas. Enseñanza de las Ciencias, 21(3), 359-370. https://doi.org/10.5565/rev/ensciencias.3914

Karpov, Y. V. (2014). Vygotsky for Educators. Cambridge University Press. https://doi.org/10.1017/CBO9781107588318

Lemke, J. L. (1997). Aprender a hablar ciencia: lenguaje, aprendizaje y valores. Ed. Paidós Ibérica.

Lemke, J. L. (1998). Multiplying meaning: visual and verbal semiotics in scientific text. In: Martin, J. R., Veel, R. (org.). (1998). Reading Science: functional perspectives on discourses of Science. London: Routledge.

Machado, V. F., \& Sasseron, L. H. (2012). As perguntas em aulas investigativas de Ciências: a construção teórica de categorias. Revista Brasileira de Pesquisa em Educação em Ciências, 12(2), 29-44.

Martins, I., Ogborn, J., \& Kress, G. (1999). Explicando uma explicação. Ensaio. Pesquisa em Educação em Ciências, 1(1), 25-38. https://doi.org/10.1590/1983-21171999010104

Moreira, H. (2018). Critérios e estratégias para garantir o rigor na pesquisa qualitativa. Revista Brasileira de Ensino de Ciência e Tecnologia, 11(1), 405-424. https://doi.org/10.3895/rbect.v11n1.6977

Penha, S. P. (2006). A Física e a Sociedade na TV. Master's Degree Dissertation, Cefet-RJ.

Penha, S. P., Carvalho, A. M. P. \& Vianna, D. M. (2015). Laboratório didático investigativo e os objetivos da enculturação científica: análise do processo. Revista de Educação, Ciência e Matemática, 5(2), 6-23.

Sasseron, L. H., \& Carvalho, A. M. P. (2011). Construindo argumentação na sala de aula: a presença do ciclo argumentativo, os indicadores de alfabetização científica e o padrão de Toulmin. Ciência \& Educação, 17(1), 97-114. https://doi.org/10.1590/S1516-73132011000100007

Sasseron, L., \& Carvalho, A. M. P. (2008). Almejando a alfabetização no ensino fundamental: a proposição e a procura de indicadores do processo. Investigações em Ensino de Ciências, 13(3), 333-352.

Tao, P. K., \& Gunstone, R. F. (1999). The process of conceptual change in force and motion during computer-supported physics instruction. Journal of Research in Science Teaching, 36(7), 859-882. https://doi.org/10.1002/(SICI)1098-2736(199909)36:7<859::AID-TEA7>3.0.CO;2-J

Vianna, D. M., \& Bernardo, J. R. R. (2012). Temas para o Ensino de Física com abordagem CTS (Ciência, Tecnologia e Sociedade). Bookmakers Ed.

\section{Copyrights}

Copyright for this article is retained by the author(s), with first publication rights granted to the journal.

This is an open-access article distributed under the terms and conditions of the Creative Commons Attribution license which permits unrestricted use, distribution, and reproduction in any medium, provided the original work is properly cited. 